\title{
Making sense of interactions between mental health and criminal justice services: the utility of cultural historical activity systems theory
}

\begin{abstract}
Purpose

Effective collaboration between mental health (MHS) and criminal justice services (CJS) impacts on mental illness and reduces reoffending rates. This paper proposes the Change Laboratory Model (CLM) of workplace transformation as a potential tool to support interagency collaborative practice that has potential to complement current integration tools used in this context. The paper focuses specifically on the theoretical dimension of the model: the cultural historical activity systems theory (CHAT) as a theoretical perspective that offers a framework with which interactions between the MHS and CJS can be better understood.
\end{abstract}

\section{Approach}

The structure and rationale behind future piloting of the change laboratory in this context is made. Then CHAT theory is briefly introduced and then its utility illustrated in the presentation of the findings of a qualitative study of leaders from mental heath and criminal justice services that explored their perspectives of the characteristics of collaborative working between mental health and prison/probation services in a Norwegian context and using CHAT as an analytical framework.

\section{Findings}

Leaders suggested that interactions between the two services, within the Norwegian system at least, are most salient when professionals engage in the reintegration and rehabilitation of the offender. Achieving effective communication within the boundary space between the two systems is a focus for professionals engaging in interagency working and this is mediated by a range of integration tools such as coordination plans and interagency meetings. Formalised interagency agreements and informal, unspoken norms of interaction governed this activity. Key challenges limiting the collaboration between the two systems included resource limitations, logistical issues and differences in professional judgments on referral and confidentiality. 
Current tools with which MHS/CJS interactions are understood and managed, fail to make explicit the dimensions and nature of these complex interactions. The CLM, and CHAT as its theoretical underpinning, has been highly successful internationally and in other clinical contexts, as a means of exploring and developing interagency working. It is a new idea in prison development, none as yet being applied to the challenges facing the MHS and CJS. This paper addresses this by illustrating the use of CHAT as an analytical framework with which to articulate MHS/CJS collaborations and the potential of the CLM more widely to address current challenges in a context specific, bottom-up and fluid approach to interagency working in this environment. 


\section{Background}

Offender rehabilitation is a key strategy employed by criminal justice services internationally to reintegrate offenders back into society and reduce reoffending rates (Norwegian Ministry of Justice, 2013; Armstrong, 2012; Skardhamar \& Telle, 2012). Offenders are encouraged to engage in education, employment, drug treatment and other interventions as part of this rehabilitation process. Offenders' mental health mediates the success with which they engage in these interventions and desist from future criminal behavior (Skeem \& Peterson, 2011). The disproportionate levels of mental illness in prison populations reported in international syntheses of prevalence statistics (e.g. 3.7\% of prisoners suffer from psychosis and $47 \%$ from personality disorder) are therefore a concern (Fazel \& Danesh, 2002) and requires professionals from mental health services (MHS) and the criminal justice system (CJS) to cross organizational boundaries to work together (Fazel \& Baillargeon, 2011; Andrews \& Bonta, 2010; World Health Organisation, 2005; Fazel \& Danesh, 2002).

A sequential intercept model outlines the points where mental health and criminal justice services work together during an offender's trajectory through the criminal justice system. These are points where the MHS and CS are most likely to overlap in their objectives and where structures need to be in place to facilitate MS/CJS interactions and easy access of the offender to mental health services. The first of these points (intercept 1 ) is at the point of arrest, when interactions fall between the police/emergency services, the mental health services and the individual. Post arrest, offenders may also be diverted from the courts and criminal justice system where possible and into mental health services (intercept 2). However, if the individual enters the prison system, then they need to have easy access to mental health services so they can receive appropriate treatment either during their court proceedings or subsequent custodial sentence (intercept 3). When nearing release, offenders need to be prepared for their transition back into society and be prepared to access community mental health services when on the outside (intercept 4). Finally ex-offenders need to receive support to maintain their mental illness and remain crime free when on the outside during their probation, parole periods and beyond (intercept 5)(Munetz \& Griffin, 2006).

Efforts to improve interagency collaboration and integration at these different points of 
intercept is in keeping with international general health and welfare service integration policy (e.g., Equity and Excellence White Paper, UK - Department of Health, UK, 2010; Norway's Coordination Reform -Department of Health and Care, Norway 2013; WHO Global Strategy on People-Centred and Integrated Health Services -World Health Organisation, 2015) but these directives have tended to bypass forensic mental health and offender rehabilitation environments, concentrating on less-complex interorganisational collaborations. Where it is acknowledged (e.g., in the US Congress of the Justice and Mental Health Collaboration Program aiming explicitly to facilitate collaboration among criminal justice, mental health treatment and substance abuse services -CSR Incorporated, 2012), little is still known about what characterises actual collaborative practice between the MHS and CJS professionals. This is despite integration and collaboration between these organisations being known to impact on reoffending rates, the financial and emotional costs incurred by the offender, the victims, their families and the tax payer (Roman, 2012;Bond \& Gittell, 2010). Researchers and practitioners need to understand these collaborative processes by making these explicit if the delivery of mental health services to the offender population is to be improved.

Steadman (1992) and Burney Nissen (2010) have called for closer scrutiny of these MHS/CJS interactions supporting specifically the systematic analysis of interorganisational workings using the concept of the boundary spanner. Boundary spanners are individuals who facilitate cross system cooperation between organisations. Their role is complex, requiring knowledge of both systems, high levels of initiative and the endorsement of all cooperating organisations (Burney Nissen, 2010). Boundary spanners require a frameworks that will help them make sense of the work that takes place in each of the collaborating institution to help them articulate the challenges that exist at the interface of the two systems and to structure innovative solutions to these.

Working with offenders and across MHS and CJS borders is a particularly complex adaptive environment where many elements interact with each other in often non-linear and unpredictable ways. It may be defined as a "wicked problem" in service planning (Rittell \& Webber, 1973), something difficult to define and that exists within open systems, influenced by a multitude of interacting influences. Multiple solutions may be available but these are each difficult to predict, test or disprove and will vary in effectiveness depending on the context and stakeholder involved. As such, any solution aimed at improving reoffending rates, rehabilitation and interagency working will resist attempts to develop standardised care pathways, structured interagency meetings or 
service level agreements between organisations that promote uniform, one size fits all coordination of care across agencies.

The first aim of this paper therefore is to present the potential of an alternative model of collaboration, the change laboratory model (CLM) particularly well suited to deal with these types of "wicked" environments. This adaptive model of interagency workplace transformation has been used successfully and extensively by researchers internationally to transform interagency working practices in a range of countries (e.g., Finland - Kerosuo \& Engeström, 2003; Brazil-Virkkunen et al., 2014) and contexts (child protection- Warmington. et al. 2005, secondary health care- Kerosuo \& Engeström, 2003 and business - Tolviainen, 2007) with a comprehensive list of products and work transformations arising from them (e.g. new adaptations of care pathways, new forms of service delivery - Virkkunen et al., 2014, ;Tolviainen, 2007; Warmington, et al. 2005). The change laboratory is a new idea in prison development, however, none as yet being applied to the challenges facing the MHS and CJS. The wickedness, complexity and unpredictability of challenges facing interagency working in these secure environments means that, before the CLM can be piloted, it still needs to be validated in this practice environment. This is the subject of an ongoing EU Commission Funded project seeking to validate the CLM in the MHS/CJS context (Horizon2020 MCA RISE COLAB Project number 734536). It is hoped that when the CLM is validated in this context and then applied and evaluated, that actual change in the way MHS and CJS services collaboration will occur.

The first step of this validation, and the first aim of this paper, is to introduce the idea of the model to the field and present its potential as an alternative means of MHS/CJS collaboration. A second step is to explore the application of the model's theoretical dimension, cultural historical activity systems theory (CHAT), as a means of interpreting collaborative practice in this context. CHAT is a tool that participants in the change laboratory intervention use to articulate and reflect on their practice. In this paper, we explore the potential this framework has within the MHS/CJS context by using the framework as a lens to interpret the findings of a small qualitative and exploratory study of the characteristics of collaborative working between Norwegian mental health and prison/probation services. Although a small study of staff working in a country specific environment, one characterised by a comparatively small prison population (2514 people serving custodial sentences in 2012 for example-Kristoffersen 2013), using this 
data serves to illustrate the use of CHAT that can be transferred to larger and other national contexts.

\section{The Change Laboratory Model}

The CLM is an intervention through which participants from different systems are brought together to reflect on their working practices in a researcher facilitated series of workshops. They do this at two levels. At the most concrete, they work at describing their current practices and its challenges using an object that mirrors their current working practice and illustrates the problems and disturbances of their work (Dimension 1 Figure 1). Videotaped work episodes as well as stories, interviews, service user feedback and regular performance statistics, collected before hand by researchers in ethnographic studies of practice, are used as this mirror. At the other end of the abstraction spectrum, participants also use theoretical models based on cultural historical activity system theory (CHAT) to conceptualize their work activity and make sense theoretically of the built-in contradictions generating the troubles and disturbances depicted in the mirror. Combining these two perspectives enables participants to identify challenges within overlapping systems and develop solutions/innovations to the contradictions they have uncovered. At this point, they return to practice to explore and test the effectiveness of their innovations, returning to further facilitated sessions to work on developing these further in a cyclical, iterative manner. Hereby a stepwise implementation of their new vision is planned and then monitored (Virkkunen \& Shelley Newnham, 2013, Engestrom, 2007). Figure 1 illustrates the relationship between the CLM intervention and the CHAT theoretical framework used within this intervention as a tool for reflection. (see Engestrom 2007 for a more detailed description of the CLM intervention and the role of the CHAT theoretical framework within it).

\section{FIGURE 1 HERE}

We advocate in this paper that the CLM be validated and evaluated in future research as a potential tool with which to promote collaboration between mental health and criminal justice services in the future. We do so for a variety of reasons. First, service leaders face policy pressures related to the delivery of integrated services and collaborative practice (UK Department of Health, 2010; Department of Health and welfare Norway2013, WHO, 2013). The CLM offers service leaders within the MHS and CJS a clear structured response to these policy drivers. This is of particular importance 
to them politically in the offender rehabilitation field when needing to respond to specific directives advocating the integrated delivery of care across organizational boundaries during the offender rehabilitation process (the Reintegration Guarantee, Norway -Sverdrup 2013, Transforming rehabilitation strategy - UK Ministry of Justice, 2013).

Secondly, the Change Laboratory Model (CLM) is potentially superior to the status quo in current MHS/CJS collaborations because in most interagency interactions the collaborative process is often only understood tacitly. The CLM however codifies this tacit knowledge. It focuses on how information is shared between professionals from different systems, the manner in which knowledge is understood across these disciplinary boundaries and combined in such a way that the two systems are best able to cocreate new ways of working. The CLM recognizes that innovation happens at the boundaries between disciplines and that working across boundaries is a key ingredient of competitive advantage (Carlile, 2004).

Current collaborative tools such as care pathways and care plans are attempts to standardise collaborative practice but each CLM is unique. Further, in current collaborative models, practice problems tend to be identified by policy makers and high level leaders. The CLM in contrast allows front line workers and service users to work together to identify and resolve issues they have identified as problematic in their own specific contexts rather than impose top down standardised solutions to what management perceive to be problematic. Problems are identified by frontline professionals and the facilitator helps them reconceptualise these. In so doing, participants gain insight direct from the mouths of people that are actually performing these collaborative activities and in their particular work place environment. Currently, solutions to collaborative practice challenges (e.g. the use of coordination tools) are management or researcher driven and adaptations of these by frontline professionals are often unintentional. The CLM, however, allows bottom up innovations to be developed. Leaders at various levels across the organsiation should still be included in these events, at least in the initial implementation phase, to provide insight into the feasibility and implementation of solutions developed by participants that are trialed back in practice after each session.

CLM participants should include both professionals and offender representatives. By actively including the offender in these organizational developmental events, the CLM 
offers offenders the opportunity to be included and valued in their contribution to service redesign. It is hypothesised that this should improve offenders' sense of empowerment and mental well being. By including the voice of the offender in the CLM, the model will be more likely to generate services/products that match the offenders' needs and motivations. They will be more likely to access mental health treatment before and after release with a longer term impact on their own health and wellbeing and potential to desist from future criminal activity. In a similar vein, the CLM has the potential in the longer term to offer participants (offenders and professionals alike) the opportunity to develop competence in social innovation and interagency collaboration. It provides a location or participants to reflect on their role in developing bottom up innovations as well as ways with which effectively to implement top down innovations that require adaptation to local contexts. It aims to develop explicitly their ability to cross the organizational and cultural boundaries between the MHS and CJS required to develop new organizational structures and systems. If MHS and CJS professionals, through involvement in a CLM, are better able to collaborate and be socially innovative in transforming their own practices, they should be better able to link the offender to the mental health services they require in a timely fashion. This means that the mental illness of the offender may be more likely to be appropriately addressed and for the offender to engage in housing, training, employment opportunities, etc., as a result. This in turn will decrease the probability of them reoffending.

It is the remit of the Horizon2020 MCA RISE COLAB Project (project number 734536) to explore the above hypotheses and the utility of the Change Laboratory as an intervention to improve MHS/CJS interactions in the long term.

\section{Cultural historical activity theory as a cognitive tool to understand criminal justice and mental health system interactions}

A key component of the CLM described above is the use of Cultural Historical Activity Theory (CHAT), a systems level theory and an evolution of sociocultural learning theory (Engeström, 2007) in which the actions of individuals are described as mediated by tools or cultural artifacts. CHAT expands this concept to suggest that the meaning we make of any one activity and its purpose (the object) is more than the individual's (or subject's-Figure 2) perceptions of these socially mediated actions. Instead the system as a whole forms the unit of analysis. The subject could be a mental health professional such as a psychiatrist and the object of their activity, for example, the assessment of a mentally ill offender. Their activity may be mediated by a range of tools, a risk 
assessment tool for example. A range of other actors (e.g. fellow psychiatrists and psychologists), or communities, within the system(s) and the way work activities are distributed between them (division of labour) may also be influential. Lastly, norms and rules such as governmental policies may constrain or facilitate the subject's workplace activities.

Whilst second generation CHAT focuses on the activity taking place within one system alone (e.g. the mental health services), third generational activity systems theory explores the overlap of two or more systems (e.g. interorganisational collaborative working between mental health and prison services) (Engeström, 2001). The point of overlap between two activity systems can be visualized in terms of a shared problem or boundary space where interorganisational learning and the transformation of interorganisational working can take place (see Figure 3). These are "spaces where the resources from different practices are brought together to expand interpretations of multifaceted tasks, and not as barriers between the knowledge and motives that characterise specialist practices"(p34) (Edwards, 2011). It is sometimes possible to identify and describe mediating artifacts within these spaces that enable continuity between the two systems. These are so called boundary objects, recognizable to both the two interacting systems. These facilitate the translation of information across organisational borders, supporting some form of coherence between systems (Star, 1989).

\section{FIGURE 2 and 3 HERE}

The CHAT framework can be used by researchers or practitioners alike, within the remit of a change laboratory, or in stand alone research, to make explicit their examination of MHS/CJS interactions, the identification of tensions that face these interactions and the development of solutions to these. Reflecting on these using the CHAT framework as a scaffold offers actors working within the CLM the opportunity for learning and organisational growth (Engeström, 2007; Engeström \& Sannino, 2011).

\section{Illustrating utility of CHAT in mental health and criminal justice system interactions}

The Norwegian context

Norwegian reoffending rates are amongst the lowest in the world (20\% - Kristoffersen, 2013). This is partially attributed to the strong rehabilitation focus in CJS here. Around 
92\% of Norwegian prisoners are diagnosed with some form of mental illness: $73 \%$ are diagnosed with a personality disorder, $28.7 \%$ have alcohol abuse issues, 51.3\% drug abuse issues, $42 \%$ suffer from anxiety, 23\% a mood disorder, 18\% have ADHD, 3.3\% psychosis and $12 \%$ are at risk of suicide (Health South East, 2014). The close association between some of these conditions and reoffending (e.g. between cluster B Personality disorders and violent reoffending-Lowenstein et al 2016), means that assessment of risk and collaboration between the MHS and CJS is a priority. Nurses and prison doctors responsible for treatment of the general population in local municipalities are also employed in prison on a part or full time basis and serve as a first source of support for mentally ill offenders. Mental health professionals employed by specialised mental health services in regional hospitals are also deployed within the prison offering mental health and substance misuse services. This is provided on a part time basis although the level of service varies from prison to prison. Further, offenders receive a reintegration guarantee from prison services (Sverdrup, 2013; Armstrong 2012), in which prison and related services are obliged to work with offenders before and on release to ensure they have access to employment, education, suitable housing accommodation, an income, medical services, addiction treatment and debt counselling. Prisons, health and welfare services work together to deliver this and formalised coordination posts have been introduced to organise this collaborative activity at a systems level (Sverdrup, 2013). These posts have a boundary spanner function. The interagency working and learning in the MHS/CJS environment that these coordinators encounter is complex and difficult to manage. Cultural Historical Activity theory (CHAT) is a key theoretical dimension of a change laboratory model that can be used to make sense of the complexity they encounter (Engeström, 2001). To illustrate this data from a qualitative study exploring collaborative practices between mental health and correctional services in a Norwegian context. The CHAT framework is used to make sense of an initial inductive thematic analysis of interviews with leaders about collaborative practice. The inductive themes (the empirical findings) are interpreted through the CHAT dimensions both as a way of synthesizing these themes into a series of metathemes and meaningful discussion. It also illustrates the use of CHAT as a cognitive tool for sense making that takes place within a CLM.

\section{Sample}

A purposeful sample ( $n=12)$ (Patton, 2002) of leaders representing equally the MHS and CJS were recruited from one of the five regions into which the Norwegian CJS is divided up nationally. Leaders were chosen for the study as firstly leaders can participate in 
CLMs as their presence facilitates the implementation of solutions developed by participants. Leaders were also chosen as individuals best placed in the first instance to provide an overview of collaborative practice between the MHs and CJS more widely. Explorations of frontline professional perspectives, however, are equally important and are currently being explored as the remit of the Horizon2020 MCA RISE COLAB Project (Project number 734536). Participants were therefore recruited on the basis of their key leadership status in the region and hence ability to give a rich, heuristic overview of each system and the collaborations between them.

The sample comprised six female and six male leaders. Regional leaders in the criminal justice services $(n=2)$, prison leaders $(n=2)$ and probation leaders $(n=1)$ were represented, as were leaders in general prison health services $(n=2)$, prison social services $(n=1)$ and specialised mental health services $(n=2)$. Individuals perceived to have overview of both the MHS and CJS systems were also included (representatives from county offices and a senior researcher in the field - $n=2$ ). Professionally these leaders were trained as lawyers $(n=3)$, social workers $(n=4)$, nurses $(n=2)$, a medical doctor, psychiatrist and family therapist.

This study formed the qualitative arm of a mixed methods study that aimed to describe collaborative systems in the Norwegian forensic health environment. The quantitative element of this wider study followed up some of the qualitative descriptions of collaborative practice presented in this paper by exploring the level and quality of contact between prison officers and specialist/generalist mental health professionals specifically in a survey of Norwegian prison officers (Hean, et al., in press).

\section{Materials and data collection}

Semi-structured interviews explored how the MHS work together with CJS in practice. The CHAT framework did not inform the initial interview questions, questions on collaboration being kept deliberately kept open and asking participants to describe collaboration between mental health and criminal justice services in general. To delve deeper into the subject matter, follow-on questions related to the range of services involved, specific structures in place to promote collaboration, the nature of relationships between services and what facilitated or constrained how they worked together. The interviewer kept a reflective diary (Patton 2002) on the conduct of the interview. The interviews were at the workplace of respondents, 1-11/2 hours in duration. The interviews were conducted in English by the first author but together 
with a Norwegian-speaking colleague (second author) to clarify language issues arising. In two cases, respondents requested a colleague to attend to assist with language issues.

\section{Analysis}

Interviews were transcribed verbatim and analysed in parallel to data collection in order that emerging themes could be more fully explored in future interviews. Interview tapes, transcripts and quotations were anonymised. Analysis was conducted QSR NVivo 10 to manage the data. An inductive thematic analysis was conducted following methods recommended by Graneheim \& Lundman, (2004). This involved familiarisation, identification of meaning units (usually a sentence or groups of sentences that captures a single concept or idea) and assigning each meaning unit a brief heading summarising its meaning in an open coding process. These codes were grouped into higher-level categories, clearly rationalising membership of each in a constant comparison of these. Sub themes and themes were constructed from the categories in a process of abstraction. Finally these themes were grouped together in metathemes using the CHAT framework as an analytical tool. The initial analysis, creation of categories and themes and overall description of each theme was shared with a panel of qualitative Norwegian researchers to confirm the trustworthiness of the categorisation and abstraction process (Shenton, 2004). An illustration of the analytical process is provided in Table 1. Quantification of the themes was kept to a minimum in the analysis in keeping with the constructivist philosophy of qualitative approach to research (see Maxwell, 2010), however, where presented, these figures cannot claim any form of generalizability beyond the realm of the small sample presented here to illustrate the utility of the CHAT perspective.

Ethical clearance was obtained from the Privacy Ombudsman for research, the Norwegian social science data service (NSD) (Ref nr: 39534) and separately from the Director of the Criminal Justice region being investigated (Vår ref: 201313560-5).

\section{TABLE 1 HERE}

\section{Presentation of interview findings: Mental health/criminal justice interactions from a CHAT perspective}

Although, interactions between the MHS and CJS were discussed at all points in the offender's trajectory through the criminal justice system and by all of the participants, it was the collaboration between organisations when offenders are serving their sentence 
and rehabilitation and reintegration back into the community that was focus for all the MHS and CJS leaders interviewed. In other words, it is the intercept between prison and the transition back into community services (intercept 4), (Munetz \& Griffin, 2006) including mental health services, which was most in the fore front of the minds of these Norwegian participants when they described collaborative practice between the MHS and CJS. This may because structures such as diversion schemes (intercept 2), mental health courts (intercept 3 ) or crisis intervention teams (intercept 1 ) have not yet been developed within the Norwegian system.

Themes that arose from the analysis (See Table 1) were subsequently grouped under five main meta-themes, metathemes informed by the CHAT framework:

- The work goals and objectives salient to each system during collaborative interagency activity

- Moving into the boundary space

- Tools mediating activity within the boundary space

- Norms and Rules within the boundary space

- Contradictions within activity systems

The meaning of these themes and meatathemes are described below:

\section{METATHEME 1: Work goals and objectives salient to collaborative workplace activity in each system.}

Themes that arose from interview data showed leaders to be describing their identification and prioritisation of offenders' needs and the mapping and mobilization of resources to address these. They believed that engaging the offender is paramount to the success of these two activities. From a CHAT perspective, these activities can be rearticulated as the objects (or perceived purpose) of individual professionals when working within their MHS and CJS activity system respectively (see Figure 1).

All participants talk of their collaborative practices they describe working centrally on the identification and prioritisation of offenders needs, a process of familiarisation with either the needs of each individual offender or the more generalised needs of a group of offenders. At the level of the individual offender, familiarisation occurs through professionals actively soliciting information from the offender uniprofessionally. In other words, when leaders talk about their work with a mentally ill offender, they speak first of their uniprofessional activity within their respective MHS or CJS activity system, working in parallel but in isolation from the other system. Participants described how, 
for prison staff, prisoner needs are identified at the entrance interview when the offender is admitted to prison or when the offender seeks help proactively (e.g., self referral to the prison nurse). For specialised mental health staff, identification of needs takes place when offenders are admitted to secure wards in the hospital after referral from prison staff or in active outreach activity when professionals from the MHS go into the prison on regular weekly scheduled visits. Respondents report offenders to have multiple, interdependent and changing needs, each difficult to untangle one from the other. Participants believed that professionals having limited resources, must prioritise these needs, dealing with the acute needs of the offender first before moving onto those that are longer term. For an offender with a mental illness, sheltered housing needs may take precedence over employment needs, for example.

Four of the leaders in the sample explained how CJS professionals specifically address the needs identified in offenders by mapping the offender's existing resources (e.g., locating the offender's family doctor in the home municipality. They then describe how they mobilise these resources by working with the offender to reestablish or repair their connections with these resources. They alternatively seek to establish new links for the offender with health and welfare resources to supplement the offender's existing support network.

If it is not acute then the whole thing will be put on hold and when they are getting ready to be released. Just before they are released, we try to get the inmate to maybe call his psychologist, to say I'm coming back (prison nurse)

Participants described how staff in specialised services explore the treatment that should be provided (e.g., medication, cognitive behavioural therapy) and where this treatment is best delivered (in the prison or hospital secure ward). At a systems level, leaders from both systems map existing services supporting particular groups of offender and seek to fill service gaps where these exist.

It is about reestablishing or maintaining. There can be broken relations. As part of the mapping it will be evident that there are a lot of things that have been present in the past which we can reestablish (probation social worker)

Engaging the offender and the collaboration between the professional and offender is central to all respondents in their discussions They describe this professional-offender 
relationship as particularly difficult during early contact with the criminal justice system when the professional is unfamiliar with the motives and history of the offender. This is especially the case when acute conditions present themselves and it is unclear the reasons behind disruptive behaviour and hence the appropriate course of action (e.g. is the offender pretending, withdrawing from drugs, mentally ill, afraid?).

Respondents describe offenders' stay in prison as a valuable opportunity to work with them in a controlled environment. But no matter how good the collaborative efforts between professions and organisations in addressing offenders' rehabilitation needs, professionals recognise that without offender cooperation within the network, interorganisational and interprofessional collaboration efforts are doomed to fail: an offender may be recommended a doctor in the home municipality, for example, before the offender's release but the individual may choose not to attend the scheduled appointment when on the outside; they may resort to substance misuse despite being enrolled on a substance misuse programme prior to release and housing provided may be abandoned in favour of homelessness or alternative accommodation. It is important therefore to build positive relations between the actors in the network and the offender, to develop feelings of trust and develop plans in which offender choice and ownership is paramount.

\section{METATHEME 2: Moving into the boundary space}

Five leaders describe professionals being driven to collaborate with other organisations by feelings of shared purpose and when facing similar challenges and interdependent goals (for example the police and mental health services both need to deal with violent, aggressive offenders). From a CHAT perspective, this means professionals move into the boundary space between their two systems (see Figure 2). Participants discussed how for CJS professionals, collaboration is needed during periods of uncertainty when they do not know how to proceed with the treatment of the offender. They believe that CJS professionals recognize the skills and expertise of professionals in other systems and the importance of these to the delivery of their own work activity. Leaders believed that the need for help from other organisations is exacerbated in situations when the offender is in a state of crisis (often early on in incarceration). At a systems level, interorganisational support is required when leaders identify critical gaps in service provision. They acknowledge they cannot stand alone. These events may be interpreted as drivers that push professionals into moving into the boundary space where the two systems overlap. 
We are not the experts. They are the experts. We need their help. The health system is important and we can't do it alone (Prison leader)

Leaders describe on the other hand how mental health professionals are at times uncertain of the treatment to provide particular group of offenders and look to experts within their own field in other regions for novel ways to treat this group. Similarly, they may seek out assistance from other organisations when implementing their treatment programmes aimed at an offender group in a particular location (in the prison or municipality for example).

You were talking about the municipality..... friendship between with municipality and specialized services. We want so much to get further ...to get out in the municipality with this programme. How do we connect with the municipality after prison? (Mental health leader)

But for collaboration to occur, leaders recognise that people from other activity systems must enter the boundary space as well: respondents wished for greater engagement of certain professions/organisations with offenders and express disappointment when this did not occur. At an individual level, they discuss the low motivation, commitment and attendance of individual professionals at leadership meetings or meetings with the offender (e.g. lack of attendance of the general medical doctor from the municipality in multiagency meetings or the prison officer at planning meetings with offender). At an organisational level, the importance of engagement of municipal/community services is particularly noted.

If we could get every partner to come here and have meetings with us, with NAV (Norwegian Welfare Department), with the home municipality, the person ..... (Prison leader)

In Figure 2, the boundary space between the MHS and CJS activity systems can be visualized as a separate activity system in itself in which the central activity is shared by both the MHS and CJS. In this study, 6 and 8 of the 12 leaders speak respectively of communication and the sharing or allocation of responsibility as the shared objective within this boundary space activity system. Prison staff identify offenders' needs and communicate these to the professional they deem responsible for addressing this need 
(e.g., prison officers communicating an offender's mental health issue to prison nurses). Respondents describe how and why knowledge is communicated between actors and how they build networks that will provide the offender with resources and support. Professionals in the CJS communicate information on offender needs to professionals from the MHS and receive in return information on possible courses of action or the availability of resources required to address these offender needs. Participants saw the frequency, timeliness, quality and reciprocity of communication as important.

\section{METATHEME 3: Tools mediating activity within boundary space}

All the MHS and CJS leaders describe how communication within the boundary space is mediated by a range of organisational structures. From a CHAT perspective, these structures are tools that mediate the activity of communication. Leaders provided descriptions of clear care pathways when dealing with offenders with acute mental illness. Although it is not clear to what degree these pathways have been standardized, they are punctuated by a series of ad hoc events/meetings when and if offender needs arise. These may be face to face but also include prison staff phoning, writing or video linking informally with professionals from other organisations. More formalised events are also described (e.g. including scheduled intra and interorganisational meetings). Both formal and informal meetings mediate how communication and information flow between organisations takes place. This also takes place via a range of assessment or coordination tools (e.g. individualised plans (IPs), so called future planning forms) and shared electronic record systems. These structures are tools that mediate the object of communication (for greater detail of each of these tools see Table 2).

\section{TABLE 2 HERE}

\section{METATHEME 4: Norms and Rules within the boundary space activity system}

All respondents were able to describe some of the rules that are salient within the boundary space. They do so when reflecting on policy and interorganisational agreements relevant to MHS/CJS interactions. They raise the existence of local agreements at regional, county and municipal levels between local prisons, probation and a range of public and not for profit community based services. These agreements manage interorganisational working and the progress of these agreements are monitored regularly. Some of the agreements between specialised mental health services and criminal justice, directed at the delivery of specialist care for particular groups of offenders (e.g. sex offenders), were praised as working particularly well. 
In Norway, recent legislation has aimed at improving the coordination of health and social care services in general (Coordiantion Reform-Norwegian Ministry of Health Care services, 2010) but respondents only referred to this policy if raised explicitly by the interviewer. Whilst one respondent suggested the coordination reform was being used as much as possible to improve collaborative practice, other respondents indicated there were areas of this reform that had not performed as expected: for example the continued lack of optimum integration of drugs and mental health services. They suggested this shortfall was due to the focus of the reform on the integration of somatic rather than mental health services. Participants describe a lack of services, resources and bed spaces in the municipality as also overriding the intention of the reform to integrate services and that this lack of resource in the community hindered the transition of individuals from institutions (including prisons and hospitals) back into community care.

Less formally, respondents describe norms mediating communication activity. These unstated rules include those governing referrals between organisations. Respondents described a referral done in writing (rather than through an oral referral over the phone for example), as a clear sign from the referrer that the request is urgent and immediate action is required. Similarly, at a systems level, financial and resource investment by an organization into a programme or service is seen to symbolize the engagement or commitment of organisations to any collaborative project. For example, investment into new modern premises for low status sex offenders was thought by respondents to be a signal from prison authorities of the importance of this group and to encourage professionals to work with them. Professionals, by not answering emails or losing paperwork or organisations failing to engage in services or programmes, was also viewed as symbolising their lack of willingness to collaborate.

\section{METATHEME 5: Contradictions/challenges within activity systems}

Challenges to working within the boundary space were discussed by all MHS and CJS leaders. Three leaders, for example, describe professionals holding alternative professional interpretations/judgments of rules governing the boundary space. They saw collaboration as being impeded if professional judgment is not congruent across organisations. This is illustrated first in relation to how they described differences in professional judgment on need for referral. Prison doctors, for example, were described as needing to make a decision on whether an offender has reached a threshold level of 
mental illness for referral to specialised mental health services. Psychiatrists within specialised mental health services on the other hand were felt often to take an alternate view on that threshold. As key gatekeepers to specialist services, these specialist mental health professionals then deny offenders access to specialist services outside of the prison on the grounds they are not sufficiently ill. Secondly, alternative understandings of confidentiality laws were discussed by participants who saw these differences as hindering communication activity and the transfer of necessary information on offenders' mental health between MHS and CJS. They described how health professionals need to exercise professional judgment about what information should be shared with the prison officer to enable the latter to do their job effectively whilst still protecting the offenders' privacy and rights to confidentiality. However, participants describe instances whereby, despite signed consent being given by the offender for the MHS to share information, the MHS professionals fail to do this and information on an assessment is not forthcoming. This makes it difficult for the prison to manage the care and behaviour of the offender in an appropriate way. The above is a failure in horizontal communication. Communication may also fail vertically, and is illustrated when this sample of leaders described how information or directives agreed by interorganisational meetings, at a systems or leadership level, may not filter vertically down to the frontline professional.

Two respondents were particularly aware of the limitations of local agreements and the balance to be achieved between the implementation of these and offender centric care. There was a stated preference for working at the level of the offender and addressing individual needs rather than more system level approaches presented by the agreement. For example, local agreements may be set in place for municipal services to receive a set number of offenders over a stipulated time period but the number of offenders and date of accessing the service upon release varies with offender compliance and eventual release date. Both of these can be unpredictable and compromises the utility of the agreement. Respondents showed an awareness of the tension between a need for regulation and standardisation of collaborative practices versus offender centred care. Standardisation on the one hand ensures the reliability and equity with which services are coordinated and integrated continuous care experienced. One the other hand, the complexity and uniqueness of each offender means providers need to map and maintain offender networks tailored to each individual.

A final contradiction mentioned by seven of the leaders, and within the boundary space, 
is the lack of use of the individualised plan (IP) as a coordination tool with which to mediate communication (see Table 1). Respondents believe there to be little implementation of this tool in the criminal justice context and respondents fall back on their silo specific tools, when no IP is available. They believe the IP may be difficult to implement especially as prisoners move around between one prison and another during their sentence. Individual plans were felt to be resource intensive and that offenders may not want one in the first place. Professionals see the IP as valuable in principle as a tool to mediate collaborative activity and as a consolidation of other plans but implementation is problematic.

There is no reference in the interviews to any shared resources being devoted to collaborative activity. Six of the respondents discuss instead how limited human resources constrains the capacity of organisations to engage in the collaborative tasks of mapping and addressing offenders' needs. They describe how in prisons only the most needy receive a full interagency needs assessment because of the limited number of social work staff available to perform this role, although prison officers may be engaged to perform a similar function. Similarly, they talk of the limited capacity in the police force as restricting the number of offenders who can be transported from prison to specialised mental health services in the regional hospital and that the municipality at times are not able to release staff to come to the prison to address the needs of a particular individual. CJS leaders also suggested that a lack of engagement by other services may be the result of them wishing temporary respite from the offender during the period of their sentence. Limited housing places in the municipality, limited beds in community services, the need to make savings in current times of austerity, no service being available in the home area that an offender is being returned to and the fact that offenders needs are complex, and addressing their needs cost intensive, were other instances mentioned where opportunities for collaboration are lost.

Three leaders discussed how logistics constrain collaborative opportunities between collaborating professionals. They describe specifically how Incompatible working schedules of professions in each organisation and the geographical distances between the prison on the one hand and community and specialised services on the other, means that building the network of collaborators around the offender is challenging. They feel also that this is the case because, for reasons of security, the services are encouraged to come to the prison rather than the offender being transported, at expense, out of the prison. They understand, however, that a lack of time resource and distance to the 
prison makes this challenging for these services.

\section{Discussion of descriptions of collaborative practice between mental health and criminal justice services using a CHAT perspective.}

Cultural-historical activity (CHAT) theory is a cognitive tool that may be used in interventions such as the change laboratory model and research alike as an aid for reflection with which to gain insight into the characteristics of collaboration between the CJS and MHS. It enables researchers and practitioners to articulate the workplace and collaborative activity between the MHS and CJS in a systematic and structured manner. It can serve then as a useful reflective tool to identify where and between which components of the system challenges lie and facilitate the design of solutions to address these.

In the illustrative example of MHS/CJS interaction in the Norwegian context as described by a sample of MHS and CJS leaders, applying the CHAT framework highlights that MHS and CJS professionals find interorganisational collaboration most salient when working on activities related to offender rehabilitation and the preparation of mentally ill offenders for release. During this time, workplace activity for MHS and CJS professionals focuses on identifying and prioritising offenders' needs, mapping and mobilising resources or providing treatment within the confines of their own system. These activities however are coordinated with the activities of the other two systems and it is around the coordination of these activities that interprofessional and interorganisational collaboration takes place. At this point, professionals enter a shared boundary space because of common values and challenges related to offender rehabilitation and when recognizing their work with the offender relies on the input of another service. The boundary space may be seen as an activity system itself, in which the main objective or activity of focus is interagency and/or interprofessional communication, where interdependent activity is coordinated through constant, timely and reciprocal information sharing (Thomson, 1967; Bond and Gittell, 2010). Heron and Reason (2008) distinguish between presentational and propositional ways in which learners gain knowledge. In these interviews, knowledge communicated between professionals is often propositional in nature (i.e. information is communicated explicitly either verbally or in writing between collaborators) (Heron and Reason, 2008). However, leaders also described communication that is symbolic or presentational in nature: the importance that is placed implicitly on a written rather then verbal referral is one example. The unspoken symbolism of a sex offender service 
being delivered in a newly constructed building, symbolising the importance of working with these offenders, is another. Future work to improve MHS/CJS interactions should take into account the improvement in both types of communication.

Communication activity within the boundary space is currently mediated by a range of tools that facilitate interagency communication (e.g. service level agreements, coordination tools such as joint individual care plans). Similar tools will be recognisable in other national contexts (e.g. Multiagency public protection arrangements-MAPPA in UK)(Ministry of Justice, 2012). These are boundary objects (Star, 1998) that facilitate communication in the boundary space.

The above themes illustrate how CHAT can be utilized to organize and articulate current collaborative practice between the MHS and CJS. This clarity will help professionals in future CLMs reflect on their collaborative activity and identify where challenges lie and find their own solutions to these, rather than wait for top down directives from researchers or policy makers. Although respondents had not been introduced to CHAT during the interviews, some preliminary contradictions or tensions within the activity systems were already obvious to them. Some of these challenges related to logistics and resource issues preventing professionals from entering the boundary space at all (e.g. lack of resource). Other challenges relate to the range of professionals engaged in communication activities and the alternative professional judgments they hold on issues of referral and confidentiality. Referral may be a contradiction within the system where professionals question the division of labour between agencies (i.e. whose responsibility is the mentally ill offender: the MHS or CJS dependent on the severity of their illness?). In other cases, professionals disagree on the norms and rules that govern confidentiality or find the rules spelt out by local interorganisational agreements not always useful, needing to find a better balance between standardised and bespoke care for mentally ill offenders.

The failure of current integration tools to effectively manage these challenges and communication between agencies is particularly notable. The ineffectiveness of current integration tools, such as the individualised plan for example, is not confined to the MHS/CJS context. In Norway, for example, individualised care plans have only been implemented in $0.5 \%$ of the general population (Bjerkan et al., 2011) when the intended target was 3\%. The reason for this lack of uptake of current integration tools, in the MHS/CJS context at least, may lie in respondents descriptions of having to weighing up 
the desirability of standardized care (e.g. standardized care, coordination tools and service level agreements), against the need to provide a bespoke service to address the unique nature of each offender and their challenges. Solutions need to be found to help professionals find the balance between these opposing pressures.

The difficulty in getting some of the integration devices described above to work in practice and the gap between what organisations expected of other organisations and what occurred in reality, may also partially be explained by the concept of street-level bureaucracy (Lipsky, 1980). Front line professionals in public services function with high levels of discretion and autonomy. Policies imposed upon them "top-down" often did not correspond to the specific client or work situation they encounter. In response, they develop coping mechanisms whereby they have to adapt or ignore the policy structures imposed upon them. Professionals failing to convene or attend scheduled interagency meetings between the MHS and CJS, claiming a lack of resource, is typical of this.

A lack of attendance or effectiveness of interagency meetings in finding solutions to current challenges in integration and interagency collaboration, may also occur because there is little guidance on who should convene and lead these and the processes that should take place within them. With this in mind, it leaves opportunity for a new way of collaborating that has the flexibility and bottom up potential to address these challenges, namely the change laboratory model.

\section{Conclusions}

The change laboratory model has been presented as an alternative model of interagency collaboration between mental health and criminal justice system. The model has potential to impact on the integration of services in the interest of the mentally ill offender and is characterized by a bottom up in approach, includes the voice of the offender and is explicit about the interagency processes it fosters. This potential now remains to be tested in situ. Beginning this process means that the value of a key tool of reflection within the change laboratory model, the Cultural-Historical Activity Systems theory, be explored. To achieve this, this paper applied this theory to a description of collaborative practice by a sample of MHS and CJS leaders. This highlighted that interactions between the two services, within the Norwegian system at least, are most salient when professionals engage in the reintegration and rehabilitation of the offender. This suggests efforts to improve MHS/CJS interactions would be best focused on this 
point in an offender's trajectory primarily. Communication within the boundary space between the two systems is a focus of interagency working and is mediated by a range of integration tools such as coordination plans and interagency meetings. Formalized interagency agreements as well as informal, unspoken norms of interaction govern this activity and should be carefully examined in situ by professionals from both agencies to identify where challenges in their collaborations lie. Key challenges limiting the collaboration between the two systems include limited resource, logistical issues and differences in professional judgments on referral and confidentiality. However, current tools aimed at improving working between the mental health and criminal justice systems are not be enough to resolve these. This leadership perspective presented here now needs to be compared and contrasted with that of front line professionals and most importantly the offender themselves in future explorations of this boundary space to expand further on the validation and testing of the feasibility of change laboratory models in the forensic mental health context as an alternative tool with which to mange interagency collaboration to better address offender rehabilitation.

\section{REFERENCES}

Andrews, D., \& Bonta, J. (2010). The Psychology of Criminal Conduct. New Jersey: Matthew Bender \& Company, Inc., LexisNexis Group.

Armstrong, S. (2012). Reducing Reoffending : Review of Selected Countries, Edingburgh: SSCJR.

Bjerkan, J., Richter, M., \& Grimsmo, A. (2011). "Integrated care in Norway: State of affairs years after regulation by law". Journal of Integrated Care, Vol 11, January, pp1-8

Bond, B. J., \& Gittell, J. H. (2010). "Cross-agency coordination of offender reentry: Testing collaboration outcomes". Journal of Criminal Justice, Vol 38 No. 2, pp118-129.

Burney Nissen, L. (2010), “Boundary spanners revisited: A qualitative inquiry into crosssystem reform through the experience of youth service professionals," Qualitative Social Work, Vol. 9 No. 3, pp. 365-384.

Carlile, P. R. (2004). "Transferring, Translating, and Transforming: An Integrative Framework for Managing Knowledge Across Boundaries". Organization Science, Vol 15, No 5, pp555-568.

Department of Health, UK. (2010). Equity and Excellence: Liberating the NHS. London: Department of Health.

Department of Health and Care, Norway (2013). Tomorrow's Care (Morgendagens omsorg): Norwegian Governement White Paper no. 29. Oslo: Norwegian Department of Health 
and Care

Engeström, Y. (2007). "Putting Vygotsky to work: The Change laboratory as an applicaiton of double stimulation". In H. Daniels, M. Cole, \& J. Wertsch (Eds.), The Cambridge Companion to Vygotsky. Cambridge.: Cambridge University Press.

Engeström, Y. (2001). "Expansive Learning at Work: Toward an activity theoretical reconceptualization". Journal of Education and Work, Vol 14, No.(1), pp133-156.

Engeström, Y., \& Sannino, A. (2011). "Discursive manifestations of contradictions in organizational change efforts: A methodological framework". Journal of Organizational Change Management, Vol 24. No. 3, pp368-387.

Fazel, S., \& Baillargeon, J. (2011). "The health of prisoners". Lancet, Vol 377, No. 9769, pp956-65.

Fazel, S., \& Danesh, J. (2002). Serious mental disorder in 23000 prisoners: a systematic review of 62 surveys. Lancet, Vol 359, No. 9306, pp545-50.

Graneheim, U. H., \& Lundman, B. (2004). Qualitative content analysis in nursing research: Concepts, procedures and measures to achieve trustworthiness. Nurse Education Today, Vol 24, No.2, pp105-112.

Hean, S., Willumsen, E., \& Ødegård, A. (in press). "Improving collaboration between professionals supporting mentally ill offenders" International Journal of Prison Health

Kerosuo, H., \& Engeström, Y. (2003). "Boundary crossing and learning in creation of new work practice". Journal of Workplace Learning, Vol 15, No. 7/8, pp345-351.

Kristoffersen R. (2013) Correctional Statistics of Denmark, Finland, Iceland, Norway and Sweden 2008 - 2012. Oslo: KRUS.

Lipsky, M. (1980). Street-Level Bureaucracy:Dilemmas of the Individual in Public Services, . US: Russel Sage Foundation.

Lowenstein, J., Purvis, C. and Rose, K. (2016), "A systematic review on the relationship between antisocial, borderline and narcissistic personality disorder diagnostic traits and risk of violence to others in a clinical and forensic sample", Borderline personality disorder and emotion dysregulation, Vol 3, No.4, pp1-12.

Maxwell, J.A. (2010), "Using Numbers in Qualitative Research," Qualitative Inquiry, Vol. 16 No. 6, pp. 475-482

Ministry of Justice, UK. (2012). MAPPA Guidance. London: Ministry of Justice.

Ministry of Justice, Norway (2013), Transforming Rehabilitation A Strategy for Reform 
Transforming Rehabilitation : A Strategy for Reform. Oslo: Ministry of Justice.

Munetz, M.R. and Griffin, P.A. (2008). "Use of the Sequential Intercept Model as an Approach to Decriminalization of People With Serious Mental Illness," Psychiatric Services, American Psychiatric Association, Vol. 57 No. 4, pp. 544-549.

Patton, M. Q. (2002). Qualitative research and evaluation methods (3rd ed.). Thousand Oaks, CA US: Sage.

Rittel, H. W. J. ., \& Webber, M. M. (1973). "Planning problems are wicked problems". Policy Science, Vol 4: pp 155-169.

Roman, J. (2013). "Cost-benefit analysis of criminal justice reforms". National Institute of Justice Journal , Vol 272, September, pp31-38

Shenton, A. (2004). "Strategies for ensuring trustworthiness in qualitative research projects". Education for Information, Vol 22, pp63-75.

Skardhamar, T., \& Telle, K. (2012). "Post-release Employment and Recidivism in Norway". Journal of Quantitative Criminology, Vol.28, No. 4, pp629-649.

Skeem, J., \& Peterson, J. (2011). "Major Risk Factors for Recidivism Among Offenders with Mental IIIness. Report prepared for the Council of State Governments (CSG)". Available at: http://riskreduction.soceco.uci.edu/index.php/publications-all/published- riskassessments/

Steadman, H. J. (1992). "Boundary spanners: A key component for the effective interactions of the justice and mental health systems". Law and Human Behavior, Vol 16, No. 1, pp75-86.

Tolviainen, H. (2007). "Interorganisational leaning across levels: an object orientate approach". Journal of Workplace Learning, Vol 19, No.6, pp343-358.

Virkkunen, J., \& Shelley Newnham, D. (2013). The Change Laboratory. Rotterdam: Sense Publishers

Virkkunen, J., Vilela, R. A. de G., Querol, M. A. P., \& Lopes, M. G. R. (2014). "O Laboratório de Mudança como ferramenta para transformação colaborativa de atividades de trabalho: uma entrevista com Jaakko Virkkunen. Saúde E Sociedade, Vol 23, No. 1, pp336-344.

Warmington, P., Daniels, H., Edwards, A., Brown, S., Leadbetter, J., Martin, D., ... Popova, A. (2005). Learning in and for interagency working: a developmental work research intervention. 4th International Conference on Researching Work and Learning, $\mathrm{pp}$ 1-10.

World Health Organisation. (2005). Mental Health and Prisons: Information Sheet, 1-6.

Retrieved from http://www.who.int/mental_health/policy/mh_in_prison.pdf

World Health Organisation. (2015). Global Strategy on People-centred and Integrated Health Services. Geneva: WHO. 
